\title{
Dietary ZnO nanoparticles alters intestinal microbiota and inflammation response in weaned piglets
}

\author{
Tian Xia ${ }^{1}$, Wenqing Lai ${ }^{1}$, Miaomiao Han ${ }^{1}$, Meng Hann ${ }^{1}, \mathrm{Xi} \mathrm{Ma}^{1}$ and Liying Zhang ${ }^{1}$ \\ ${ }^{1}$ State Key Laboratory of Animal Nutrition, China Agricultural University, Beijing, China \\ Correspondence to: Xi Ma, email: maxi@cau.edu.cn
}

Liying Zhang, email: zhangliying01@sina.com

Keywords: nano zinc oxide, antioxidant enzyme, inflammation response, intestinal microbiota, weaning piglet, Immunology and Microbiology Section, Immune response, Immunity

$\begin{array}{lll}\text { Received: March 12, } 2017 & \text { Accepted: April 19, } 2017 & \text { Published: May 04, } 2017\end{array}$

Copyright: Xia et al. This is an open-access article distributed under the terms of the Creative Commons Attribution License 3.0 (CC BY 3.0), which permits unrestricted use, distribution, and reproduction in any medium, provided the original author and source are credited.

\section{ABSTRACT}

The present study was carried out to determine whether low dose of zinc oxide nanoparticles (Nano-ZnO) could serve as a potential substitute of pharmacological dose of traditional $\mathrm{ZnO}$ in weaned piglets. 180 crossbred weaning piglets were randomly assigned to 3 treatments. Experimental animals were fed basal diet supplemented with $0 \mathrm{mg} \mathrm{Zn/kg} \mathrm{(Control),} 600 \mathrm{mg} \mathrm{Zn/kg} \mathrm{(Nano-ZnO)} \mathrm{and} 2000 \mathrm{mg}$ $\mathrm{Zn} / \mathrm{kg}(\mathrm{ZnO})$ for 14 days. On day 14 after weaning, the piglets fed Nano-ZnO did not differ from those fed traditional ZnO in growth performance and jejunal morphology, while Nano-ZnO treatment could significantly alleviate the incidence of diarrhea $(P$ $<0.05$ ). In jejunum, the mRNA expressions of intestinal antioxidant enzymes and tight junction proteins were increased $(P<0.05)$ in Nano-ZnO treatment. In ileum, the expression levels of IFN-Y, IL-1 $\beta$, TNF- $a$ and NF-KB were decreased $(P<0.05)$. Gene sequencing analysis of $16 \mathrm{~S}$ rRNA revealed that dietary Nano-ZnO increased the bacterial richness and diversity in ileum, while decreased both of them in cecum and colon. Specifically, the relative abundances of Streptococcus in ileum, Lactobacillus in colon were increased, while the relative abundances of Lactobacillus in ileum, Oscillospira and Prevotella in colon were decreased $(P<0.05)$. In conclusion, our data reveal that low dose of Nano-ZnO $(600 \mathrm{mg} \mathrm{Zn/} \mathrm{kg)} \mathrm{can} \mathrm{effectively} \mathrm{reduce} \mathrm{piglet}$ diarrhea incidence, similar to high dose of traditional ZnO (2000 mg Zn/ kg), which may be mediated by improving intestinal microbiota and inflammation response in piglets, and help to reduce zinc environmental pollution.

\section{BACKGROUND}

Weaning is commonly associated with oxidative stress, barrier dysfunction and the perturbation of gut microbiota especially in weaned piglets, which is responsible for the growth retardation, villus atrophy and diarrhea $[1,2]$. In current animal husbandry industry, pharmacological dose of dietary $\mathrm{ZnO}$ (2000-3000 mg $\mathrm{Zn} / \mathrm{kg}$ ) has been widely used due to its efficient function on promoting growth and relieving diarrhea of weaned piglets. Moreover, these functions may be accomplished by improving barrier function, regulating oxidation state, modulating immune response and altering microbiota [3]. However, pigs consume relatively higher level of $\mathrm{Zn}$ will excrete more in urine and feces, which raises concerns on environmental pollution [4], and causes negative evaluation of $\mathrm{ZnO}$ using in weaned piglets diet.

Nano- $\mathrm{ZnO}$ is an inorganic zinc product ranging in particle size from 1 to $100 \mathrm{~nm}$. It has been reported that Nano-ZnO differed from ordinary $\mathrm{ZnO}$ due to its unique chemical and physical properties, including the effect of volume, surface, quantum size and macro quantum tunnel [5], in addition, Nano-ZnO only partly dissolved in gastric fluid in vivo [6], and showed a limited solubility in neutral environments [7]. Thus, Nano- $\mathrm{ZnO}$ is likely absorbed as the intact particulate form and as zinc ions [8]. Studies about Nano- $\mathrm{ZnO}$ application mainly focused on the hazards or toxicity in a dose- and time-dependent manner, which was probably caused by reactive oxygen species, oxidant injury or excitation of inflammation [9]. In addition, a wide range of antibacterial activities with the 
damage of bacterial cell membrane has also been studied [10]. It has been demonstrated that Nano-ZnO moderated the antioxidant activity and revealed an excellent antiinflammatory property by suppressing the expression of inflammatory cytokines in a dose-dependent manner. Nano-ZnO supplementation has been demonstrated to increase gain weight, feed conversion and improve the antioxidant capacity in broilers [11]. An enhancing immune response of cows was also found [12].

The present study aimed to evaluate whether the low level of Nano-ZnO has a comparable effect of pharmacological dose of $\mathrm{ZnO}$ on benefitting piglet health. Our research revealed that the positive function of Nano$\mathrm{ZnO}$ might be accomplished by improving intestinal morphology, regulating the expressions of antioxidant enzymes, tight junction proteins, growth marker genes and inflammatory cytokines, and modulating bacterial community.

\section{RESULTS}

\section{Dietary Nano-ZnO improved growth performance and jejunal morphology of weaned piglets}

Feed:gain of weaning piglets in traditional $\mathrm{ZnO}$ treatment was significantly lower than that in the control group $(P<0.05)$, but did not differ from that in the Nano$\mathrm{ZnO}$ treatment $(P>0.05)$. Incidence of diarrhea was alleviated by the addition of Nano- $\mathrm{ZnO}$ and traditional $\mathrm{ZnO}$ when compared with the control group $(P<0.01)$, while piglets in Nano-ZnO treatment had higher diarrhea incidence than piglets in traditional $\mathrm{ZnO}$ group $(P<0.05)$. No significant differences were found in average daily gain and average feed intake among treatments $(P>0.05)$ (Table 1).

Jejunal villus height and the ratio of villus height to crypt depth of weaning piglets fed traditional $\mathrm{ZnO}$ were significantly higher than piglets in the control group $(P<0.05)$, but showed no significant difference when compared with Nano-ZnO treatment $(P>0.05)$ (Figure 1A). There was no significant difference in crypt depth of jejunum among treatments $(P>0.05)$ (Table 2$)$.

\section{Dietary Nano-ZnO activated the expression of Cu-Zn SOD, GPX1, ZO-1, Occludin and MT in the jejunal tissues}

Compared with the control group, dietary supplementation with Nano- $\mathrm{ZnO}$ and traditional $\mathrm{ZnO}$ significantly increased the relative mRNA expressions of $\mathrm{Cu}-\mathrm{Zn}$ SOD, GPX1, ZO-1 and Occludin in jejunum $(P<$ $0.05)$. Moreover, their expressions in Nano-ZnO treatment were lower than those in traditional $\mathrm{ZnO}$ treatment $(P<$
$0.05)$. In addition, the relative MT mRNA expression by 5.4 or 270.4 fold was increased after supplementing Nano$\mathrm{ZnO}$ and traditional $\mathrm{ZnO}$, and interestingly, the relative mRNA expression of MT in the traditional $\mathrm{ZnO}$ group was dramatically higher than that in other two groups $(P<$ 0.05) (Figure 1B-1C).

\section{Dietary Nano-ZnO improved the expression of inflammatory cytokines in the jejunal and ileal tissues}

Compared with the control, the relative mRNA expression of CDK4 was elevated but the relative mRNA expression of Caspase 3 was reduced by Nano-ZnO and traditional $\mathrm{ZnO}$ significantly $(P<0.01)$. While the mRNA expression of CDK4 in the Nano-ZnO treatment was significantly lower than that in the traditional $\mathrm{ZnO}$ group $(P<0.05)$. The mRNA expression of IGF-1 was increased by traditional $\mathrm{ZnO}$ compared with the control group $(P<$ $0.05)$, but no significant differences were found in mRNA expression of IGF-1 between traditional $\mathrm{ZnO}$ and Nano$\mathrm{ZnO}$ treatments $(P>0.05)$ (Figure 1D).

Dietary supplementation with Nano-ZnO and traditional $\mathrm{ZnO}$ significantly decreased the relative mRNA expression of IFN- $\gamma$, IL- $1 \beta$, TNF- $\alpha$ and NF- $\kappa$ B in comparison to control animals $(P<0.01)$. The mRNA expression of IFN- $\gamma$, TNF- $\alpha$ and NF- $\kappa$ B did not differ between Nano- $\mathrm{ZnO}$ and traditional $\mathrm{ZnO}$ treatments $(P$ $>0.05)$, while as to IL-1 $\beta$, Nano-ZnO was significantly higher than the traditional $\mathrm{ZnO}$ treatment $(P<0.01)$. When detected the expression of IL-6, the results showed that this in the traditional $\mathrm{ZnO}$ group was significantly lower than the control group $(P<0.01)$, but did not differ from the Nano-ZnO treatment $(P>0.05)$. No significant difference was found in TGF- $\beta$ among treatments $(P>$ 0.05) (Figure 1E).

\section{Dietary Nano-ZnO altered the richness and diversity of bacterial community in the ileal, cecal, and colonic contents}

After size filtering, quality control and chimera removal, a total of 690231,696240 , and 748887 valid sequences in the ileal, cecal, and colonic contents were obtained respectively. While valid sequences in the ileal, cecal, and colonic digesta showed no significant difference among treatments $(P>0.05)$ (Figure 2A). Operational taxonomic unit (OUT) numbers of bacterial community were classified from valid sequence with $97 \%$ similarity. OTUs, Chao 1 value and Shannon index of bacterial community were significantly higher in Nano$\mathrm{ZnO}$ and traditional $\mathrm{ZnO}$ treatments $(P<0.05)$ (Figure 2B), but lower in the colonic content $(P<0.05)$ (Figure 2B3-2D3). In addition, the OTUs and Chao 1 value in the cecal content were markedly decreased by Nano-ZnO 
A
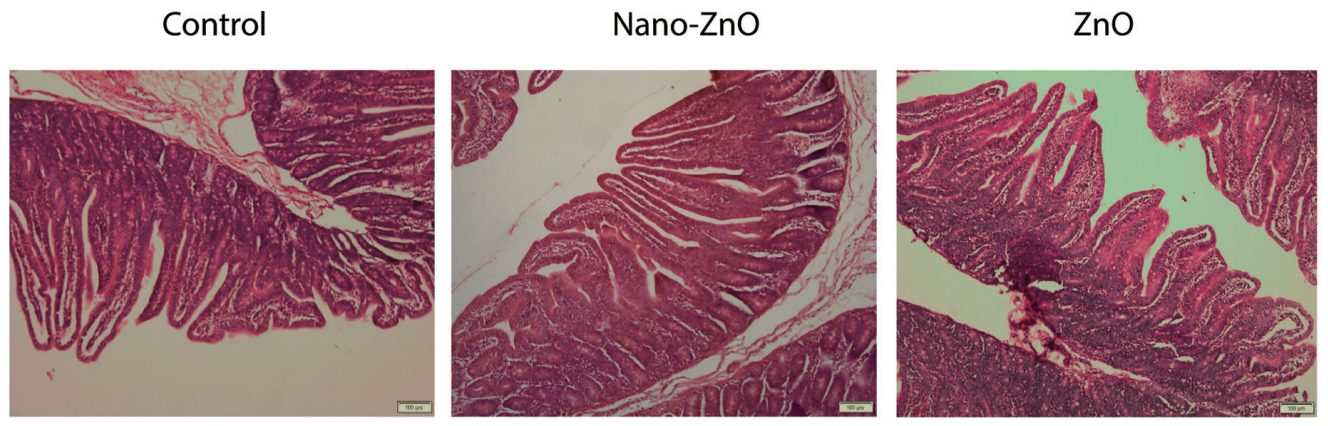

D
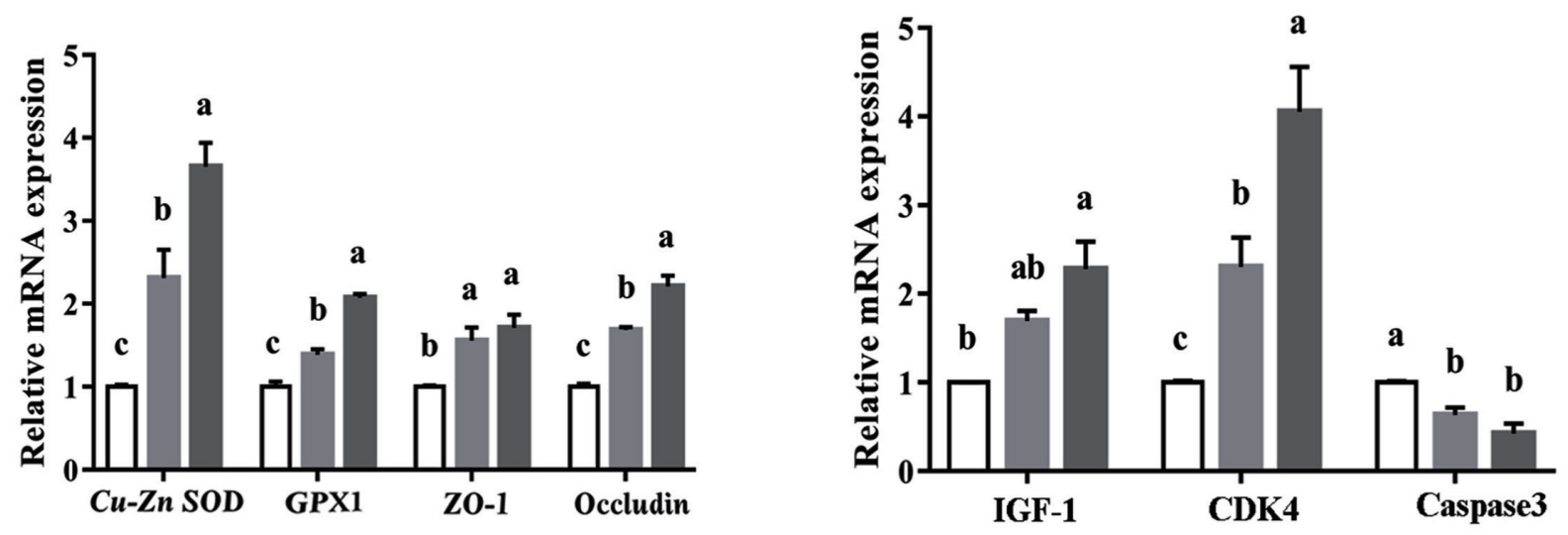

C

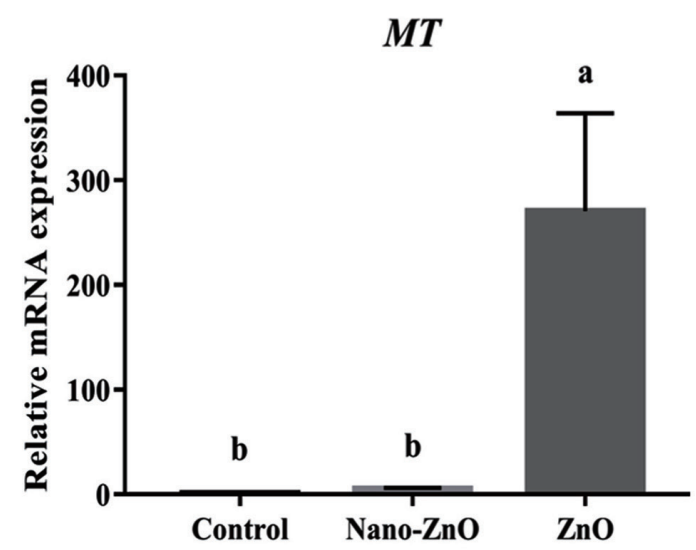

$E$



Figure 1: The effects of $\mathrm{ZnO}$ treatments on intestinal morphology, and the ralative mRNA expressions of intestinal antioxidant enzymes, tight junction proteins and inflammatory cytokines. A. The jejunum in different groups were stained by HE. Histology images of jejunal morphology were collected. B. The relative mRNA expressions of Cu-Zn SOD, GPX1, ZO-1, and Occludin were detected. As to MT, its relative mRNA expression was also measured in jejunum $\mathbf{C}$. The relative mRNA expressions of IGF-1, CDK4 and Caspase 3 in jejunum of weaning piglets were also measured D.. In addition, the IFN- $\gamma$, IL-1 $\beta$, IL-6, TNF- $\alpha$, NF- $\mathrm{kB}$ and TGF- $\beta$ were detected by quantitative RT-PCR E.. $\beta$-actin was used as an internal standard for normalization. Values are means \pm SEMs, $n$ $=6$. Different superscripts within each group mean significant difference $(P<0.05)$. Control, corn-soybean meal basal diet; Cu-Zn SOD, $\mathrm{Cu}-\mathrm{Zn}$ superoxide dismutase; GPX1, glutathione peroxidase 1; MT, metallothionein; IGF-1, insulin-like growth factor 1; Nano-ZnO, cornsoybean meal basal diet supplemented with $600 \mathrm{mg} \mathrm{Zn/kg}$ as nano zinc oxide; $\mathrm{ZnO}$, corn-soybean meal basal diet supplemented with 2000 $\mathrm{mg} \mathrm{Zn} / \mathrm{kg}$ from zinc oxide. 
and traditional $\mathrm{ZnO}(P<0.01)$ (Figure 2B2-2C2), and the OTUs and Chao 1 value showed no significant difference between Nano-ZnO and traditional $\mathrm{ZnO}$ treatments $(P$ $>0.05)$. However, the Shannon index in the traditional
$\mathrm{ZnO}$ treatment was significantly lower than other two treatments $(P<0.01)$ (Figure 2D2).

The PCA with unweighted UniFrac distances presents discrepancy among samples. The samples
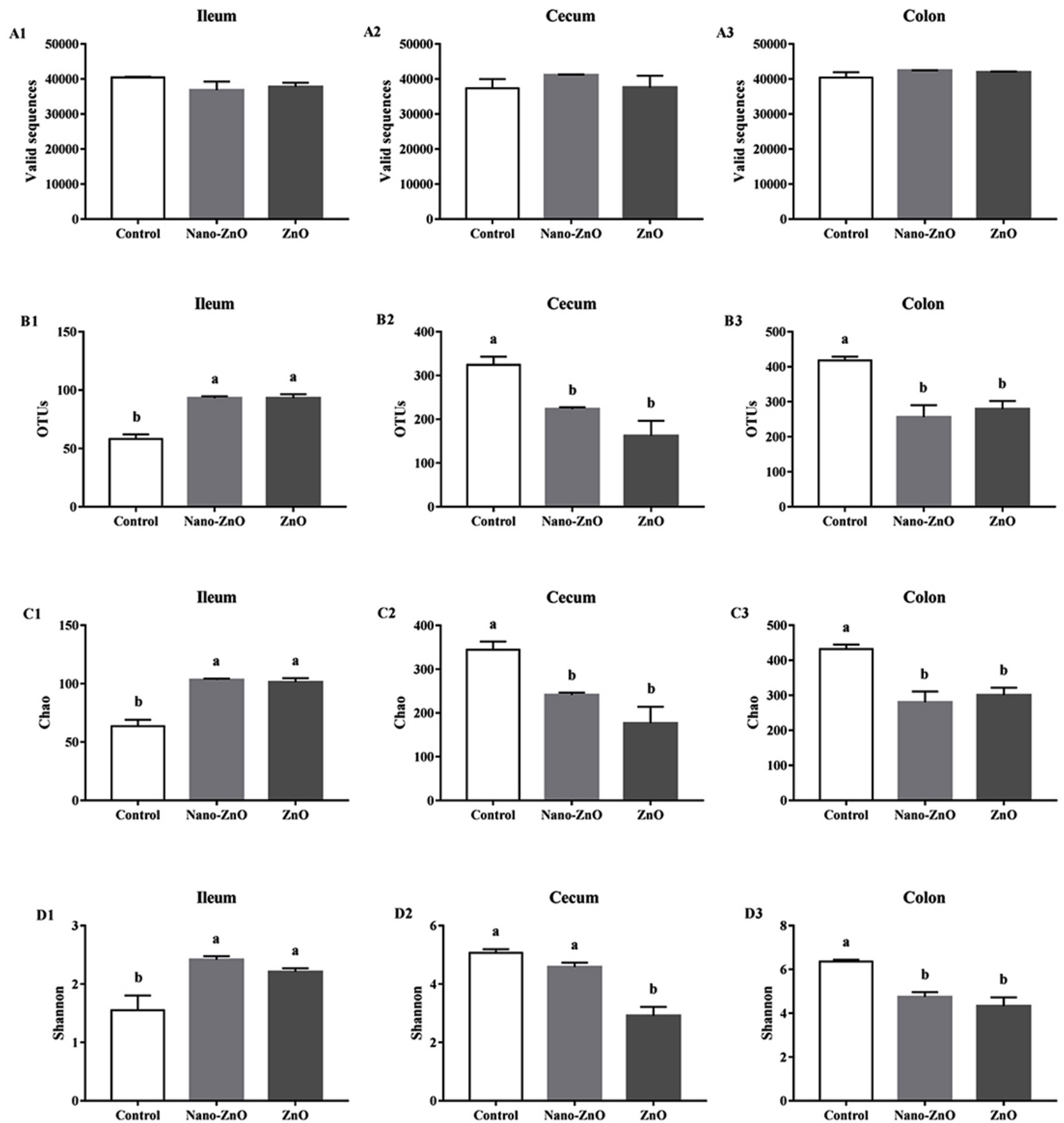

Figure 2: The richness and diversity of bacterial community in the ileal, cecal and colonic contents of weaning piglets. Valid sequences A. and operational taxonomic units (OTUs) B. were clustered from sequences with similarity scores $\geq 0.97$ respectively in ileum, cecum, and colon. The microbiota richness was estimated by Chao 1 value and the estimates in ileum, cecum and colon were all gained C.. Shannon index could indicate the bacterial diversity, which was measured among ileum, cecum and colon separately D.. Values are means \pm SEMs, $n=3$. Mean values followed by different letters differ significantly, $P<0.05$. Control, corn-soybean meal basal diet; Nano-ZnO, corn-soybean meal basal diet supplemented with $600 \mathrm{mg} \mathrm{Zn/kg}$ as nano zinc oxide; ZnO, corn-soybean meal basal diet supplemented with $2000 \mathrm{mg} \mathrm{Zn/kg}$ from zinc oxide. 
Table 1: Growth performance and diarrhea incidence in weaning piglets. ${ }^{1}$

\begin{tabular}{|l:c:c:c:c:c}
\hline \multicolumn{1}{|c}{ Variable } & Control & Nano-ZnO & ZnO & SEM & $P$ value \\
\hline Initial body weight, $\mathrm{kg}$ & $7.43 \pm 0.13$ & $7.47 \pm 0.13$ & $7.36 \pm 0.15$ & 0.24 & 0.96 \\
\hline Final body weight, $\mathrm{kg}$ & $11.6 \pm 0.32$ & $12.1 \pm 0.24$ & $12.0 \pm 0.29$ & 0.50 & 0.77 \\
\hline Average daily gain, $\mathrm{g}$ & $330 \pm 29.6$ & $341 \pm 29.7$ & $344 \pm 31.7$ & 16.0 & 0.34 \\
\hline Average daily feed intake, g & $471 \pm 35.3$ & $476 \pm 33.9$ & $473 \pm 36.7$ & 21.3 & 0.51 \\
\hline Feed:gain & $1.44 \pm 0.02^{\mathrm{a}}$ & $1.41 \pm 0.02^{\mathrm{ab}}$ & $1.38 \pm 0.02^{\mathrm{b}}$ & 0.01 & 0.02 \\
\hline Diarrhea, $\%$ & $11.0 \pm 0.06^{\mathrm{a}}$ & $6.67 \pm 0.45^{\mathrm{b}}$ & $2.36 \pm 0.40^{\mathrm{c}}$ & 1.02 & $<0.01$ \\
\hline
\end{tabular}

${ }^{1}$ Values are means \pm SEMs; $n=36$ for initial body weight and final body weight; $n=6$ for average daily gain, average daily feed intake, feed: gain and diarrhea. Mean values in the same row with different superscript letters differ significantly, $P<$ 0.05 .

Table 2: Jejunal Morphology of weaning piglets. ${ }^{1}$

\begin{tabular}{|c|c|c|c|c|c|}
\hline Variable & Control & Nano-ZnO & $\mathrm{ZnO}$ & SEM & $P$ value \\
\hline Villus height, $\mu \mathrm{m}$ & $327 \pm 7.32^{\mathrm{b}}$ & $340 \pm 6.89^{\mathrm{ab}}$ & $353 \pm 8.78^{a}$ & 9.06 & 0.05 \\
\hline Crypt depth, $\mu \mathrm{m}$ & $148 \pm 5.36$ & $145 \pm 4.73$ & $146 \pm 5.18$ & 6.09 & 0.69 \\
\hline Villus height: crypt depth & $2.22 \pm 0.07^{\mathrm{b}}$ & $2.35 \pm 0.08^{\mathrm{ab}}$ & $2.43 \pm 0.07^{\mathrm{a}}$ & 0.04 & 0.04 \\
\hline
\end{tabular}

${ }^{1}$ Values are means \pm SEMs, $n=6$. Mean values in the same row with different superscript letters differ significantly, $P<0.05$.

clustered according to intestinal segments, and foregut's (ileal) samples separated with hindgut's (cecal and colonic) ones obviously (Figure 3), indicating that there were distinct differences in bacterial community between foregut and hindgut.

\section{Dietary Nano-ZnO improved the baterial community structures in the ileal, cecal, and colonic contents}

16S rRNA profiles for each experimental group in the ileum, colon and cecum were very dissimilar. The

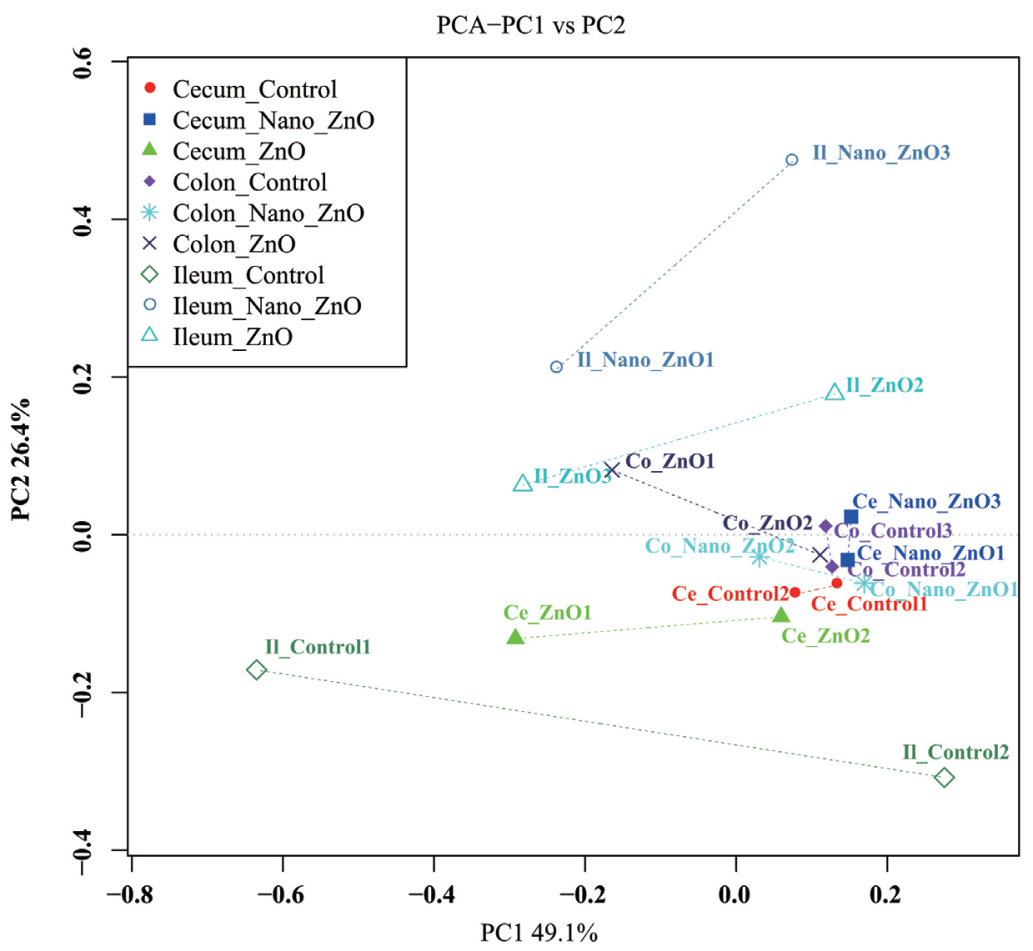

Figure 3: Ileal, cecal and colonic principal coordinate analysis (PCoA) and Venn diagrams of bacterial communities. Unweighted PCoA by ileal and colonic bacterial microbiota. Ce-/Co-/Il-control, the cecal/colonic/ileal digesta in the control treatment; $\mathrm{Ce}-/ / \mathrm{Co}-/ \mathrm{Il}-\mathrm{Nano}-\mathrm{ZnO}$, the cecal/colonic/ileal digesta in the Nano-ZnO treatment; Ce-/Co-/Il-ZnO, the cecal/colonic/ileal digesta in the $\mathrm{ZnO}$ treatment. 
Table 3: Ingredients and chemical compositions of the basal diet. ${ }^{1,2}$ (g/kg as fed)

\begin{tabular}{|c|c|c|c|}
\hline Ingredient composition & & Chemical analysis & \\
\hline Corn & 597 & Digestible energy ${ }^{2}(\mathrm{MJ} / \mathrm{kg})$ & 14.9 \\
\hline Soybean meal & 90 & Dry matter & 873 \\
\hline Soy protein concentrate & 110 & Crude protein & 204 \\
\hline Fish meal & 47 & Calcium & 8.2 \\
\hline Whey powder & 100 & Total phosphorus & 6.7 \\
\hline Soybean oil & 10 & $\mathrm{Zn}^{3}(\mathrm{mg} / \mathrm{kg})$ & 112 \\
\hline Sodium chloride & 3 & Lysine & 16.0 \\
\hline Dicalcium phosphate & 8.2 & Methionine & 5.5 \\
\hline Limestone & 6.8 & Methionine + Cysteine & 8.7 \\
\hline L-Lysine $\cdot \mathrm{HCl}(78 \%)$ & 5.5 & Threonine & $\begin{array}{l}9.7 \\
\ldots \ldots\end{array}$ \\
\hline DL-Methionine $(98.5 \%)$ & 2.7 & Tryptophan & 2.6 \\
\hline L-Threonine & 2.1 & Valine & 10.1 \\
\hline L-Tryptophan & 0.6 & & \\
\hline L-Valine & 1.0 & & \\
\hline Choline chloride & 2.0 & & \\
\hline Sodium bicarbonate & 8.7 & & \\
\hline Vitamin-mineral premix ${ }^{1}$ & 5.0 & & \\
\hline
\end{tabular}

${ }^{1}$ Provided the following per $\mathrm{kg}$ of diet : 12,000 IU Vitamin A, 3,000 IU Vitamin $\mathrm{D}_{3}, 30$ IU Vitamin E, $2.5 \mathrm{mg}$ Vitamin $\mathrm{K}_{3}, 2.5$ $\mathrm{mg}$ Thiamine, $4.0 \mathrm{mg}$ Riboflavin, $3.0 \mathrm{mg}$ Pyridoxine, $0.02 \mathrm{mg}$ Vitamin $\mathrm{B}_{1}, 40 \mathrm{mg}$ nicotinic acid, $12.5 \mathrm{mg}$ pantothenic acid, $0.7 \mathrm{mg}$ folic acid, $0.07 \mathrm{mg}$ biotin, $100 \mathrm{mg} \mathrm{Fe}\left(\mathrm{FeSO}_{4} \cdot \mathrm{H}_{2} \mathrm{O}\right), 150 \mathrm{mg} \mathrm{Cu}\left(\mathrm{CuSO}_{4}\right), 90 \mathrm{mg} \mathrm{Zn}\left(\mathrm{ZnSO}_{4}\right), 55 \mathrm{mg} \mathrm{Mn}\left(\mathrm{MnSO}_{4}\right)$, $0.25 \mathrm{mg} \mathrm{I}(\mathrm{KI}), 0.30 \mathrm{mg} \mathrm{Se}\left(\mathrm{Na}_{2} \mathrm{SeO}_{3}\right)$.

${ }^{2}$ All values were obtained from triplicate except digestible energy. Analyzed concentration of zinc in the basal diet. The experimental diets contained zinc at 701 and $2079 \mathrm{mg} / \mathrm{kg}$, respectively.

OTU composition and abundance were relatively similar between the colon, ileum and cecum content in the same treatment groups (Figure 4A). Meanwhile, Venn diagrams were constructed to represent the shared richness among the ileal, cecal, and colonic digesta samples (Figure 4B4D). Much more unique OTUs were detected among the ileal, cecal, and colonic digesta samples as well.

The ileal microbiota in weaning piglets mainly consisted of the Firmicutes and Proteobacteria at phylum level. The supplementation of Nano- $\mathrm{ZnO}$ caused notable shifts in relative abundance, consisting of a decrease in Firmucutes and an increase in Proteobacteria after $14 \mathrm{~d}$ post-weaning $(P<0.05)$ (Figure $5 \mathrm{~A})$.

At family level, Firmicutes were mainly composed of Lactobacillaceae, Streptococcaceae, Clostridiaceae, and Bacillaceae, while Halomonadaceae was the primary family of Proteobacteria (Figure 5B). Lactobacillaceae was the richest family in the control group, but its proportion dropped dramatically from $94.08 \%$ to $30.37 \%$ and $46.17 \%$ after adding Nano- $\mathrm{ZnO}$ and traditional $\mathrm{ZnO}$ $(P<0.01)$. On the contrary, the relative abundances of Streptococcaceae and Bacillaceae significantly increased, from $2.47 \%$ to $51.44 \%$ and $45.36 \%$ and from $0.74 \%$ to $3.12 \%$ and $1.88 \%$, respectively $(P<0.01)$. In addition, the increased abundance of Proteobacteria in the Nano-
$\mathrm{ZnO}$ treatment was mainly due to a significant increase of Halomonadaceae.

At genus level, Lactobacillus, Streptococcus, Bacillus and Halomonas were predominant genera of Lactobacillaceae, Streptococcaceae, Bacillaceae and Halomonadaceae, respectively, and the changed tendencies of these genera were consistent with the tendencies of responding families as Nano- $\mathrm{ZnO}$ and traditional $\mathrm{ZnO}$ were added to the basal diet.

In the cecal contents, Firmicutes, Bacteroidetes, Proteobacteria, Tenericutes, and Actinobacteria were five major phyla of microbiota (Figure 5A). The relative abundance of Firmicutes increased from $93.05 \%$ to $97.72 \%$ when traditional $\mathrm{ZnO}$ was added to the basal diet $(P<$ 0.05 ). At family level, Firmicutes were mainly composed of Lactobacillaceae, Streptococcaceae, Lachnospiraceae, Ruminococcaceae, Erysipelotrichaceae, and Clostridiaceae (Figure 5B). In addition, S24-7, Pasteurellaceae, and Coriobacteriaceae were the primary families of Bacteroidetes, Proteobacteria and Actinobacteria, respectively. Comparing with other two treatments, the proportion of Lactobacillaceae was significantly increased by traditional $\mathrm{ZnO}$ treatment $(P<0.05)$, while the relative abundances of Lachnospiraceae, Ruminococcaceae and Erysipelotrichaceae were markedly decreased $(P<0.05)$. 
No significant differences were found in those abovementioned bacteria between the control and Nano- $\mathrm{ZnO}$ treatments $(P>0.05)$. However, we still observed that the unidentified bacteria in the Nano- $\mathrm{ZnO}$ treatment were significantly higher than other two groups $(P<0.05)$. Down to the genus level, Lactobacillus occupied an important position in Lactobacillaceae, and Streptococcus in Streptococcaceae, and their proportions varied consistently with their affiliated families. Lachnospiraceae primarily consisted of Blautia, Coprococcus, Dorea, Lachnospira, and Roseburia. Among them, the relative abundances of Dorea and Roseburia tended to show different decreases after treatment with Nano-ZnO and/ or traditional $\mathrm{ZnO}$ in the basal diet. Butyricicoccus, Faecalibacterium, Oscillopira and Ruminococcus are the main genus of Ruminococcaceae, and the proportion of

A

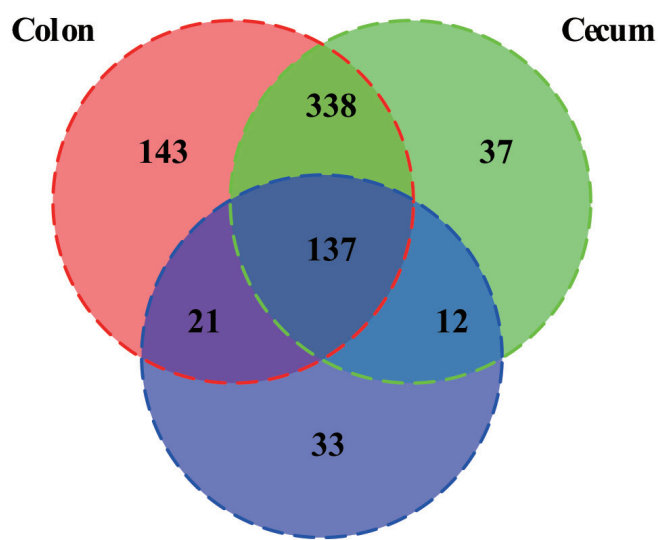

Ileum

C

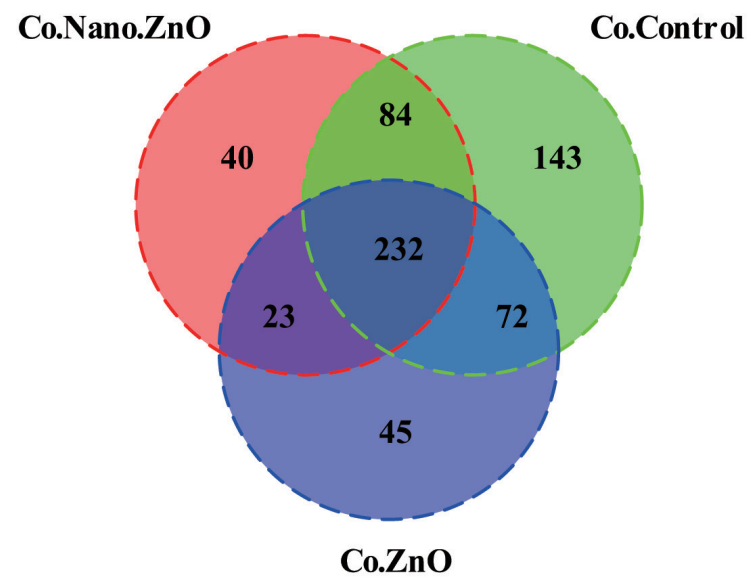

Ruminococcus was significantly decreased in Nano-ZnO and traditional $\mathrm{ZnO}$ treatments when compared with the control group $(P<0.05)$. However, there were still about $10.22 \%-27.94 \%$ cecal bacteria that were unidentified at genus level.

In the colonic contents, Firmicutes, Bacteroidetes, Actinobacteria, Proteobacteria and Tenericutes were dominant phyla (Figure 5A). When treatingg with Nano$\mathrm{ZnO}$ and traditional $\mathrm{ZnO}$, the relative abundance of Firmicutes was significantly increased $(P<0.01)$, while the abundance of Bacteroidetes was decreased $(P<$ 0.01). At family level, Firmicutes was mainly consisted of Lactobacillaceae, Streptococcaceae, Clostridiaceae, Lachnospiraceae, Ruminococcaceae, Veillonellaceae and Erysipelotrichaceae (Figure 5B). Bacteroidetes was mainly composed of Prevotellaceae, S24-7 and

\section{B}

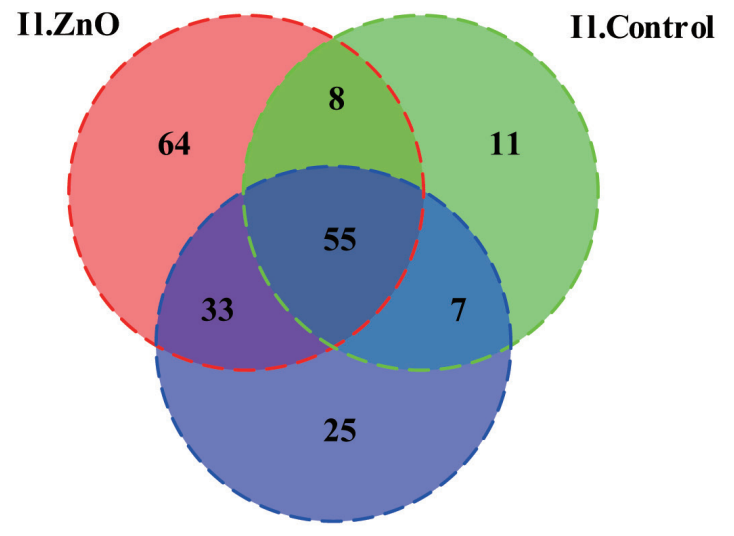

II.Nano.ZnO

D

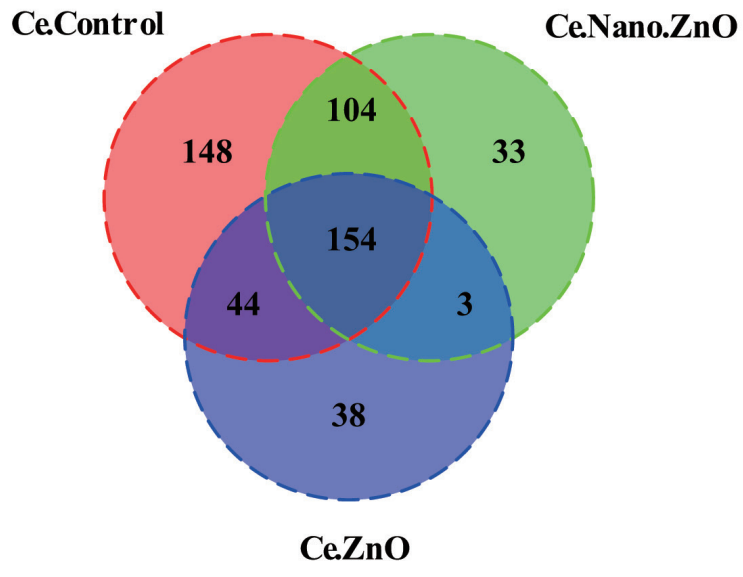

Figure 4: Venn diagrams of bacterial communities and bacterial OTUs in different parts of intestine among three treatments. A. Venn diagrams illustrating overlap of bacterial OTUs in ileal, cecal and colonic samples. B.-D. Venn diagrams illustrating overlap of bacterial OTUs in B. Ileum, C. Cecum, D. Colon among three treatments. Ce./Co./Il.Control, the cecal/colonic/ileal digesta in the control treatment; Ce./Co./Il.Nano.ZnO, the cecal/colonic/ileal digesta in the Nano-ZnO treatment; Ce./Co./Il.ZnO, the cecal/colonic/ ileal digesta in the $\mathrm{ZnO}$ treatment. 
A

Phylum

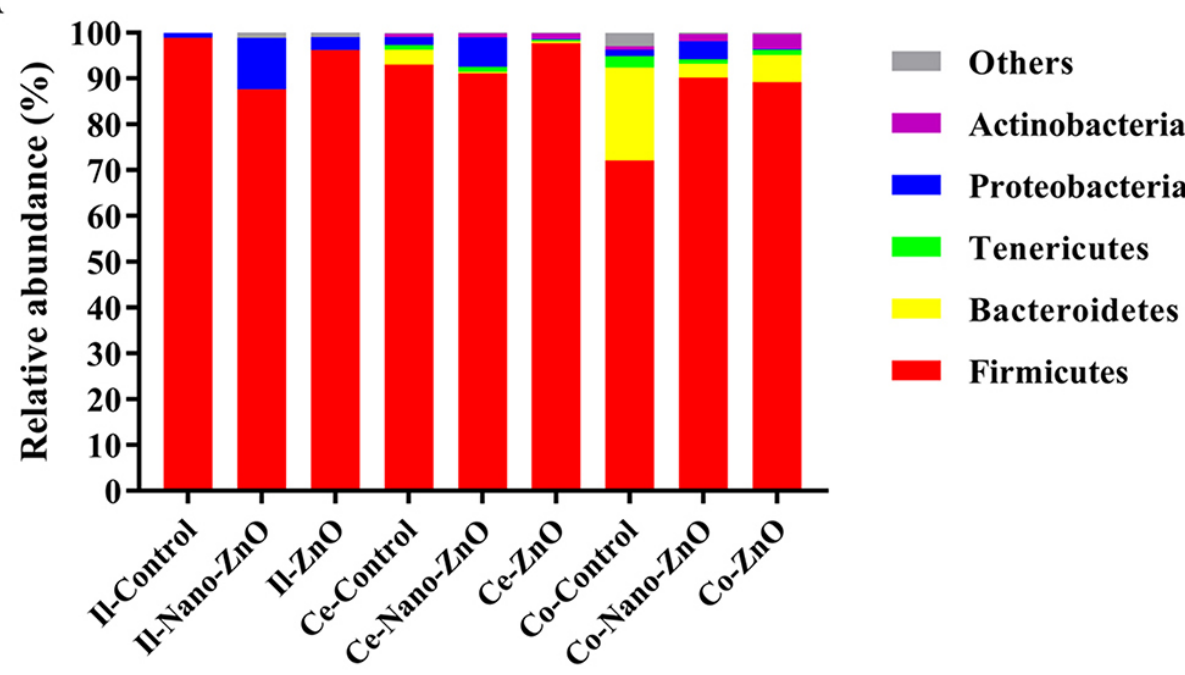

Family

B
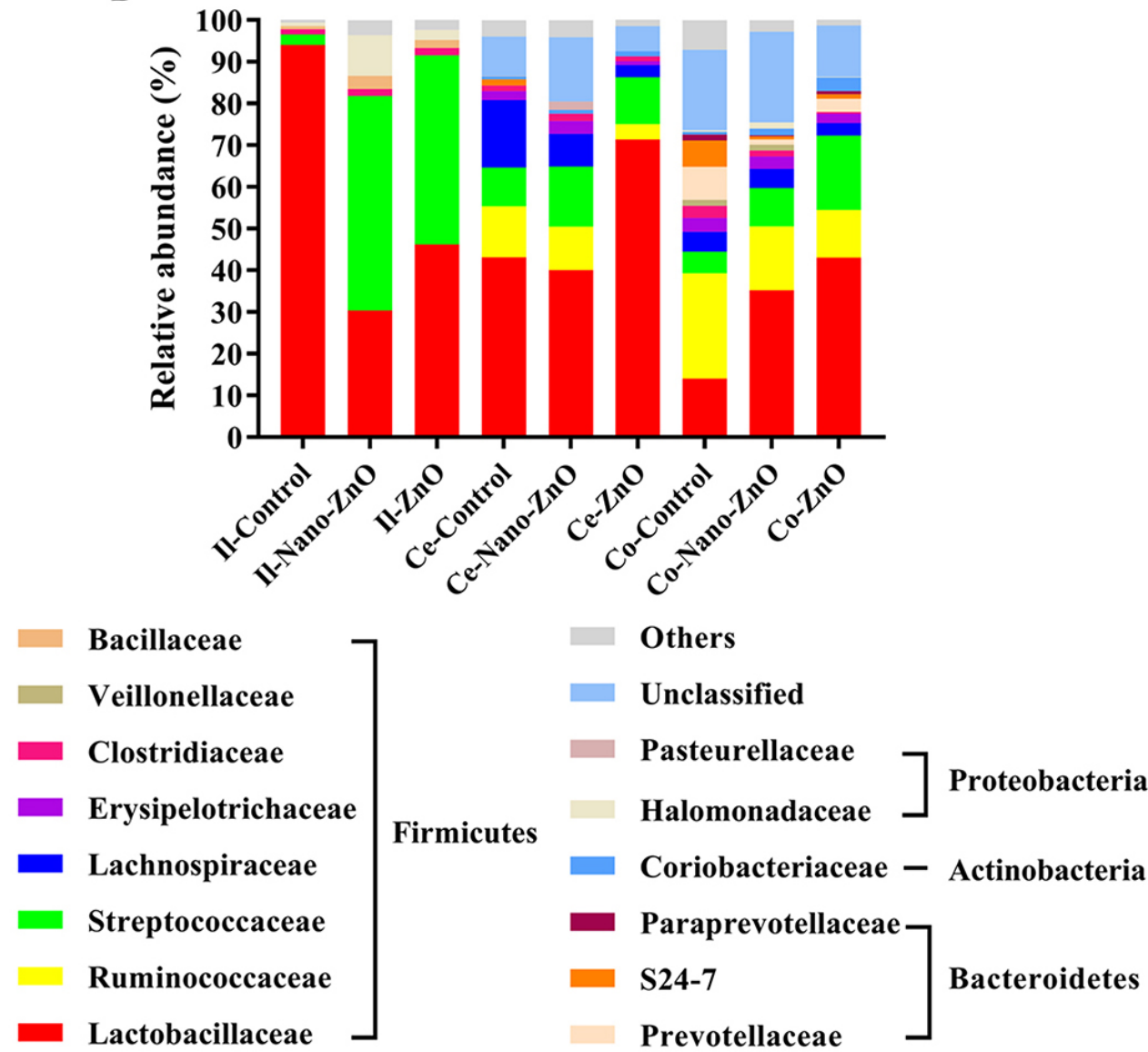

Figure 5: Effects of Nano- $\mathrm{ZnO}$ and $\mathrm{ZnO}$ on ileal, cecal and colonic bacterial community of weaning pigs. Relative read abundance of different bacterial phylum A. and families B. within different communities in the ileal, cecal and colonic digesta in different treatments was detected. Values were means, $n=3$. Phyla and families with proportion less than $1 \%$ were not listed. Control, corn-soybean meal basal diet; Nano-ZnO, corn-soybean meal basal diet supplemented with $600 \mathrm{mg} \mathrm{Zn/kg} \mathrm{as} \mathrm{nano} \mathrm{zinc} \mathrm{oxide;} \mathrm{ZnO,} \mathrm{corn-soybean} \mathrm{meal}$ basal diet supplemented with $2000 \mathrm{mg} \mathrm{Zn/kg}$ from zinc oxide. Ce-/Co-/Il-control, the cecal/colonic/ileal digesta in the control treatment; $\mathrm{Ce}-/ / \mathrm{Co}-/ \mathrm{Il}-\mathrm{Nano}-\mathrm{ZnO}$, the cecal/colonic/ileal digesta in the Nano-ZnO treatment; $\mathrm{Ce}-/ \mathrm{Co}-/ \mathrm{Il}-\mathrm{ZnO}$, the cecal/colonic/ileal digesta in the $\mathrm{ZnO}$ treatment. 
Paraprevotellaceae, and the Coriobacteriaceae and Halomonadaceae were the primary families of the Actinobacteria and Proteobacteria. Compared with the control group, the relative abundance of Lactobacillaceae in both two treatments was increased significantly $(P<$ $0.05)$, while the relative abundances of Prevotellaceae and S24-7 were markedly decreased $(P<0.05)$. In addition, by treating with traditional $\mathrm{ZnO}$, the proportion of Lachnospiraceae was significantly decreased compared to the control group $(P<0.05)$. Down to the genus level, Collinsella, Prevotella, Lactobacillus, Streptococcus, SMB53, Oscillospira, Bulleidia and Halomonas were predominant genera of Coriobacteriaceae, Prevotellaceae, Lactobacillaceae, Streptococcaceae, Clostridiaceae, Ruminococcaceae, Erysipelotrichaceae and Halomonadaceae, respectively. Piglets fed with Nano-ZnO and traditional $\mathrm{ZnO}$ diets had a higher level of Lactobacillus $(P<0.05)$ and lower Prevotella and Oscillospira $(P<0.05)$ than piglets fed with the basal diet. Compared with the control group, the relative abundance of Bulleidia was significantly reduced by adding traditional $\mathrm{ZnO}(P<0.05)$. However, the percent between $22.01 \%-41.43 \%$ of colonic bacterial community was unidentified at genus level.

\section{DISCUSSION}

Dietary pharmacological dose of traditional $\mathrm{ZnO}$ (2000-3000 mg Zn/kg) can promote growth and alleviate diarrhea, increase intestinal barrier function and alter intestinal microbiota composition in weaning piglets [13]. However, whether Nano-ZnO can improve piglet health as an alternative to pharmacological dose of traditional $\mathrm{ZnO}$ is still unknown. Herein, feed conversion efficiency in the traditional $\mathrm{ZnO}$ treatment was significantly increased when compared with the control group, which demonstrated that the pharmacological $\mathrm{ZnO}$ supplementation increased the feed efficiency during the post-weaning $\mathrm{d} 0-10$ or $\mathrm{d}$ $0-28$ [14]. No significant differences in feed conversion efficiency between Nano-ZnO group and traditional $\mathrm{ZnO}$ group were found, which indicated that Nano- $\mathrm{ZnO}$ with a dose of $600 \mathrm{mg} \mathrm{Zn} / \mathrm{kg}$ might have a similar effect to traditional $\mathrm{ZnO}$ in the concentration of $2000 \mathrm{mg} \mathrm{Zn} / \mathrm{kg}$ on improving feed efficiency in weaning piglets during post-weaning d 0-14. Incidence of diarrhea was reduced by treating with Nano- $\mathrm{ZnO}$ and traditional $\mathrm{ZnO}$, while piglets fed Nano-ZnO had a higher diarrhea incidence than piglets fed with traditional $\mathrm{ZnO}$ in this study. This result indicated that a low level of Nano- $\mathrm{ZnO}$ inclusion in diet might have a potential function in alleviating post-weaning diarrhea of weaning piglets [3]. Weaning usually changes the architecture and function of piglets gut [15], resulting in a temporary decrease in digestive and absorptive function of the small intestine. Dietary supplementation with pharmacological dose of traditional
$\mathrm{ZnO}$ has been demonstrated to improve the intestinal morphology of weaning piglets [16]. Similar results were obtained in this study that the villus height and the ratio of villus height to crypt depth of jejunum in traditional $\mathrm{ZnO}$ treatment were significantly higher than those in the control group, but did not differ from those in the Nano$\mathrm{ZnO}$ treatment. Therefore, we concluded that the moderate Nano-ZnO might have comparable effects on improving jejunal morphology to high dose of traditional $\mathrm{ZnO}$.

To reveal the potential mechanism, the intestinal barrier function was determined. The mRNA expressions of $\mathrm{Cu}-\mathrm{Zn}$ SOD, GPX1, ZO-1 and Occludin in the jejunal tissue were elevated by Nano- $\mathrm{ZnO}$ and traditional $\mathrm{ZnO}$ supplementation. However, between Nano-ZnO and traditional $\mathrm{ZnO}$, the expressions of those above genes were lower in the Nano-ZnO treatment. ZO-1 and Occludin, as key proteins of tight junction, the levels of which expression are consistently associated with the gut barrier function [17]. Our data indicated that dietary supplementation with $600 \mathrm{mg} \mathrm{Zn/kg} \mathrm{as} \mathrm{Nano-ZnO} \mathrm{may}$ be rewarding, while the concentration of $600 \mathrm{mg} \mathrm{Zn/kg}$ may have a weaker effect than pharmacological dose of traditional $\mathrm{ZnO}$ in restoring the decreased antioxidant capacity and injured barrier function in the jejunum tissue caused by weaning stress. More interestingly, traditional $\mathrm{ZnO}$, but not $\mathrm{Nnao}-\mathrm{ZnO}$, could dramatically increase the mRNA expression of MT, which is consistent with the report that intestinal mucosa cell from pigs fed 2425 or $3000 \mathrm{mg} \mathrm{Zn/kg}$ from $\mathrm{ZnO}$ for 14 or $28 \mathrm{~d}$ has the greatest concentration or mRNA expression of MT [18]. MT, associated with zinc concentration, not only serves as an antioxidant participating in protective stress responses [19], but also serves as a zinc transporter acting in zinc trafficking and zinc donation to apoproteins [20]. Supplemental traditional $\mathrm{ZnO}$ would increase the relative mRNA expression of MT by 270.4 fold, while adding Nano-ZnO would only by 5.4 fold, which further illustrated that $\mathrm{ZnO}$ nanoparticle was likely absorbed as both the zinc ions and as the intact particulate form by transcytosis $[5,13]$, and that $\mathrm{ZnO}$ nanoparticle could only partly dissolve in gastric fluid in vivo by aggregating together [13]. Gastrointestinal development of weaning piglets relays on the proliferation and differentiation of enterocytes, while the key factors regulating the intestinal development are the expressions of growth marker genes. IGF-1, which can be locally synthesized in the gastrointestinal tract, is an important mediator of the proliferation and differentiation of enterocytes [21]. CDK4 are used as markers to monitor proliferation and apoptosis in the programmed cell death due to its functions in $\mathrm{G} 1$ phase of cell cycle that CDK4 could act as a key enzyme [22]. In the current study, the relative mRNA expression of CDK4 in the jejunal tissue was significantly increased in Nano- $\mathrm{ZnO}$ and traditional $\mathrm{ZnO}$ treatments, however the mRNA expression of Caspase 3 was markedly 
decreased. The results may firstly indicate that Nano- $\mathrm{ZnO}$ and traditional $\mathrm{ZnO}$ are able to promote proliferation and inhibit apoptosis of enterocyte in the jejunum of weaning piglets. Therefore, dietary supplementation with Nano$\mathrm{ZnO}(600 \mathrm{mg} \mathrm{Zn} / \mathrm{kg}$ ) may promote enterocyte growth and inhibit enterocyte apoptosis.

In addition, the mRNA expressions of IFN- $\gamma$, IL$1 \beta$, TNF- $\alpha$ and NF- $\mathrm{KB}$ in the ileal tissue significantly decreased after supplementing Nano- $\mathrm{ZnO}$ and traditional $\mathrm{ZnO}$ into the basal diet, which was similar to previous study [23]. It has been reported that traditional $\mathrm{ZnO}$ or Nano-ZnO supplementation both significantly reduced the expression of NF- $\mathrm{KB}$ target gene in the porcine epithelial J2 (IPEC J2) cells or RAW 264.7 Macrophages [24]. The down-regulation of pro-inflammatory cytokines in the present of Nano- $\mathrm{ZnO}$ indicated that the weaning-induced inflammation was alleviated by Nano- $\mathrm{ZnO}$ at a sub- or non-toxic concentration. Furthermore, Nano- $\mathrm{ZnO}$ with the dose of $600 \mathrm{mg} \mathrm{Zn/kg} \mathrm{might} \mathrm{had} \mathrm{a} \mathrm{potential} \mathrm{function}$ that can parallel the pharmacological dose of traditional $\mathrm{ZnO}$ in regulating immune and inflammatory responses of weaning piglets [25].

In this study, gene sequencing analysis of $16 \mathrm{~S}$ rRNA disclosed variations of bacterial community in the ileal, cecal and colonic digesta. In ileum, the bacterial richness was estimated by Chao1 value and diversity was measured by Shannon index, both of which were significantly increased by dietary Nano- $\mathrm{ZnO}$ and traditional $\mathrm{ZnO}$ treatments. This result was in agreement with previous studies that richness and diversity of microbes in ileum were both elevated after adding traditional $\mathrm{ZnO}$ with $2500 \mathrm{mg} \mathrm{Zn} / \mathrm{kg}$ or $3042 \mathrm{mg} \mathrm{Zn/kg} \mathrm{[26-27].} \mathrm{In} \mathrm{the} \mathrm{control}$ treatment, Firmicutes, Lactobacillaceae and Lactobacillus dominated bacterial community at phylum, family and genus level, respectively, and their relative abundances were significantly decreased by supplementing Nano$\mathrm{ZnO}$ and/or traditional $\mathrm{ZnO}$. However, in treatments with Nano-ZnO and traditional $\mathrm{ZnO}$, the abundances of Streptococcaceae, Bacillaceae, Streptococcus and Bacillus were observed to be markedly increased. The results are consistent with reports that Firmicutes and lactic acid bacteria dominate the ileal microbiota, and traditional $\mathrm{ZnO}$ would reduce the Lactobacillus spp. [26, 28]. The theory that Streptococcus spp. seemed to quantitatively replace $L$. reuteri as a major player in the ileum was confirmed in our study to some extent for the increasing level of Streptococcus [26]. Bacillus can excellently adapt zinc environment as a consequence of spore persistence and its capacity to response to zinc concentration, which may be beneficial to piglet health [29]. The relative abundances of Proteobacteria, Halomonadaceae and Halomonas in the Nano- $\mathrm{ZnO}$ treatment were significantly higher comparing with the control group, which might mainly due to the increased proportion of Halomonas with its strong adaptation to environment rich in zinc [30] and the decreased competition caused by the decreased abundance of Lactobacillus. Furthermore, it has been reported that Nano-ZnO had a wide range of antibacterial activities [12] that may involve in both the zinc toxicity from dissolved $\mathrm{Zn}$ (II) ions [31] and the production of reactive oxygen species caused by undissolved Nano- $\mathrm{ZnO}$ in gastrointestinal tract $[13,27]$. However, the antibacterial effect of Nano-ZnO depends on dose, size, shape and other factors [31]. Therefore, both Nano-ZnO and traditional $\mathrm{ZnO}$ in this study can enrich the bacterial richness and diversity, which may be beneficial to the construction of a more stable intestinal micro-ecosystem [32].

In cecum, the bacterial richness was decreased by treating with Nano- $\mathrm{ZnO}$ and traditional $\mathrm{ZnO}$, while the bacterial diversity was only reduced in traditional $\mathrm{ZnO}$ group, which was in agreement with a previous study [22]. Moreover, it also has been investigated that the antibacterial effect of Nano- $\mathrm{ZnO}$ is dosage- and time-dependent [33]. Traditional $\mathrm{ZnO}$ supplementation (2000 $\mathrm{mg} \mathrm{Zn/kg)} \mathrm{in} \mathrm{our} \mathrm{study} \mathrm{significantly} \mathrm{increased}$ the relative abundances of Firmicues, Lactobacillaceae and Lactobacillus, and decreased Lachnospiraceae, Ruminococcaceae, Erysipelotrichaceae and Ruminococcus. However, feeding with traditional $\mathrm{ZnO}(2500 \mathrm{mg} \mathrm{Zn} /$ $\mathrm{kg}$ or $2425 \mathrm{mg} \mathrm{Zn} / \mathrm{kg}$ ) showed a decline of lactic acid bacteria in cecum [22], while no obvious changes in the abundances of the Firmicutes and Lactobacillus was observed in the cecal digesta [13]. Researchers reported that all Lactobacillaceae strains possessed the excellently high zinc resistance in vitro except L.amylovorus [32]. The decreased relative abundances of Lachnospiraceae, Ruminococcaceae, Erysipelotrichaceae and Ruminococcus might be beneficial to promote growth or alleviate incidence of diarrhea of weaning piglets [34]. Compared to the control group, Nano-ZnO treatment significantly decreased the Ruminococcus level, while compared with the traditional $\mathrm{ZnO}$ treatment, the unclassified bacterial abundance was increased. It is reported that only $14 \%$ of Nano-ZnO could dissolve in gastric fluids [13] and Nano$\mathrm{ZnO}$ had limited solubility in neutral environment [14]. In addition, Nano- $\mathrm{ZnO}$ particles are unstable in suspension of water, where they aggregate together and continue to increase size beyond the nanoscale [34]. So the limited impact of Nano- $\mathrm{ZnO}$ on cecal microbiota showed in our study might result from the low concentrations of Nano$\mathrm{ZnO}$ and zinc ions dissolved from Nano- $\mathrm{ZnO}$.

In colon, the richness and diversity of bacteria were significantly decreased in Nano- $\mathrm{ZnO}$ and traditional $\mathrm{ZnO}$ treatments, which was also consistent with a previous study [14]. Moreover, the Nano- $\mathrm{ZnO}$ particles have a wide range of antibacterial activities toward various microorganisms [35]. Dietary supplementation with Nano- $\mathrm{ZnO}$ and traditional $\mathrm{ZnO}$ significantly decreased the relative abundances of Bacteroidetes, Prevotellaceae, S24-7, Prevotella and Oscillospira and increased the relative abundances of Firmicutes, Lactobacillaceae and Lactobacillus. However, high concentration of 
dietary traditional $\mathrm{ZnO}(2500 \mathrm{mg} \mathrm{Zn} / \mathrm{kg}$ or $2425 \mathrm{mg}$ $\mathrm{Zn} / \mathrm{kg}$ ) significantly decreased the abundance of lactic acid bacteria, such as Lactobacillus spp. in colon [22]. Adding traditional $\mathrm{ZnO}$ in the concentration of $3.1 \mathrm{~g} / \mathrm{kg}$ was difficult to apparently change the abundances of the Bacteroidetes, Firmicutes and Lactobacillus [36]. Liedtke and Vahjen have reported that 10 of 11 Lactobacillaceae strains showed high zinc resistance. So the different results in different studies may result from dietary zinc contents, resistances of bacteria and so on. The relative abundances of Lachnospiraceae and Bulledia in the traditional $\mathrm{ZnO}$ treatment were significantly lower than those in the control treatment, which might contribute to reduce the diarrhea incidence [37]. The rival effect of the lower concentration of Nano- $\mathrm{ZnO}$ to pharmacological dose of traditional $\mathrm{ZnO}$ on colonic bacterial compositions may due to the relativehigh concentrated zinc concentration in colon content [38].

In conclusion, dietary supplementation with Nano$\mathrm{ZnO}$ in the concentration of $600 \mathrm{mg} \mathrm{Zn/kg}$ was effective in alleviating diarrhea, improving mRNA expressions of antioxidant enzymes, tight junction proteins and growth marker genes in jejunum, inhibiting mRNA expression of inflammatory cytokines in ileum, and regulating ileal and colonic microbiota richness, diversity and stability. Nano$\mathrm{ZnO}(600 \mathrm{mg} \mathrm{Zn} / \mathrm{kg}$ ) may be an effective alternative to pharmacological dose traditional $\mathrm{ZnO}(2000 \mathrm{mg} \mathrm{Zn} / \mathrm{kg})$ in improving piglet intestinal health.

\section{MATERIALS AND METHODS}

All procedures used in this experiment were approved by the Animal Care and Use Committee of China Agricultural University (Beijing, China). The $\mathrm{ZnO}$ content of Nano- $\mathrm{ZnO}$ used in this study was $98.6 \%$, average particle size measured by transmission electron microscopy was $23.0 \mathrm{~nm}$, crystallite size assayed by X-ray diffraction was $25.0 \mathrm{~nm}$, and the bet surface area tested was $48.9 \mathrm{~m}^{2} / \mathrm{g}$.

\section{Animals, diets, and experimental protocol}

A total of 108 crossbred piglets (Duroc $\times$ Landrace $\times$ Yorkshire) weaned at $27 \pm 1 \mathrm{~d}$ of age, with an average initial body weight of $7.42 \pm 0.80 \mathrm{~kg}$, were blocked by weight, sex and litter and were assigned to 1 of 3 dietary treatments, with 6 replicates (pens) of 6 piglets ( 3 males and 3 females). Feed (mash form) and water (nipple drinker) were available ad libitum throughout the 14-d feeding trial. The dietary treatments were corn-soybean meal basal diet (Control), corn-soybean meal basal diet supplemented with $600 \mathrm{mg} \mathrm{Zn/kg}$ as Nano-ZnO (Nano$\mathrm{ZnO}$ ) or $2000 \mathrm{mg} \mathrm{Zn} / \mathrm{kg}$ from $\mathrm{ZnO}(\mathrm{ZnO})$ at the expense of corn. The basal diet was formulated to meet or exceed the nutrient requirements of 7-11 kg pigs recommended by the NRC (2012). The ingredients and chemical compositions of the basal diet are given in Table 3.
Piglets and feed were weighed individually at the beginning and the end of the experiment. The average daily gain (ADG), average daily feed intake (ADFI), and feed:gain $(F: G)$ ratio were then calculated. Fecal consistency within each pen was visually assessed at 8:30 each day during this experiment according to the method described by Hill et al. [14]. The scoring system for consistency was as follows: $1=$ very firm, $2=$ medium firm, $3=$ moderately loose, $4=$ very loose, and $5=$ thin and watery. The occurrence of diarrhea was defined when the feces was thin and watery.

\section{Chemical analysis of the diets}

Diets were sampled at mixing and ground to pass through a $0.15-\mathrm{mm}$ sieve. Dry matter (AOAC procedure 934.01), crude protein (AOAC procedure 990.03), calcium and total phosphorus (AOAC procedure 985.01), and amino acids (AOAC procedure 151982.30 ) contents of the diets were analyzed according to the procedures of the AOAC International (2005). Zinc in diets was analyzed by Flame Atomic Absorption Spectrophotometry (AA-6300, Shimadzu Corp., Tyoto, Japan) after samples were wetdigested by using nitric-perchloric acid and diluted with deionized distilled water. The analyzed zinc contents in the control, Nano- $\mathrm{ZnO}$ and $\mathrm{ZnO}$ treatment diets were 112, 701 and $2079 \mathrm{mg} / \mathrm{kg}$, respectively.

\section{Sample collection}

At the end of the 14-day experiment, one piglet in each pen with body weight and diarrhea incidence closest to the pen average was chosen and fasted overnight (12 h). The abdomen was aseptically opened and the jejunum, ileum, cecum and colon were sampled. The digesta of ileum, cecum and colon were collected aseptically and immediately immersed in liquid nitrogen and stored at $-80^{\circ} \mathrm{C}$ for analysis of bacterial community.

\section{Intestinal histomorphometry, RNA isolation and quantitative RT-PCR analysis}

Morphological indices were determined using a Leica Image Processing and Analysis System (Leica Imaging Systems Limited, Berlin, Germany). Total RNA isolation and quantitative real-time PCR analysis was conducted as described by Shen et al. [3] with modifications. Briefly, total RNA of jejunum and ileum was extracted using the TRIzol reagent (Invitrogen) after tissue homogenization and treated with DNase I (Invitrogen Life Technologies). The integrity of the extracted RNA was checked by $1 \%$ agarose gel electrophoresis and visualisation of intact $18 \mathrm{~S}$ and $28 \mathrm{~S}$ ribosomal RNA bands under UV light. Nucleic acid concentrations were measured in triplicate with a UV/ 
Table 4: Primers used for quantitative RT-PCR. ${ }^{1,2}$

\begin{tabular}{|c|c|c|c|c|}
\hline \multirow{2}{*}{ Target } & \multicolumn{2}{|c|}{ Primers sequences, 5'-3' } & \multirow{2}{*}{ Size (bp) } & \multirow{2}{*}{ AT } \\
\hline & Forward & Reverse & & \\
\hline $\mathrm{Cu}-\mathrm{Zn} \mathrm{SOD}$ & CAGGTCCTCACTTCAATCC & CCAAACGACTTCCASCAT & 255 & 60 \\
\hline GPX1 & TGGGGAGATCCTGAATTG & GATAAACTTGGGGTCGGT & 183 & 56 \\
\hline MT & GTGAATCCGCGTTGCTCTCTGCT & CTGTGGGGCAGGAGCAGTTGG & 138 & 60 \\
\hline $\mathrm{ZO}-1$ & GAGTTTGATAGTGGCGTT & GTGGGAGGATGCTGTTGT & 298 & 52 \\
\hline Occludin & ATCAACAAAGGCAACTCT & GCAGCAGCCATGTACTCT & 157 & 56 \\
\hline Caspase 3 & TGTGTGCTTCTAAGCCATGG & AGTTCTGTGCCTCGGCAG & 158 & 58 \\
\hline IGF-1 & TGCTTCCGGAGCTGTGATCT & CCGACTTGGCAGGCTTGA & 67 & 58 \\
\hline NFKB & AGCTTGCCGTGTCTGCTGCT & CCGCCAAGGAGATGTTGTCG & 118 & 60 \\
\hline CDK4 & AGACCTGAAGCCAGAGAACATTC & AAGATACAGCCAACGCTCCAC & 195 & 60 \\
\hline IFN- $\gamma$ & GAGCCAAATTGTCTCCTTCTAC & CGAAGTCATTCAGTTTCCCAG & 140 & 56 \\
\hline TGF- $\beta$ & GGACCTTATCCTGAATGCCTT & TAGGTTACCACTGAGCCACAAT & 133 & 60 \\
\hline $\mathrm{IL}-1 \beta$ & TGAAGTGCCGCACCCAAAACCT & CGGCTCCTCCTTTGCCACAATCA & 175 & 62 \\
\hline IL-6 & CCTGTCCACTGGGCACATAAC & CAAGAAACAACCTGGCTCTGAAAC & 253 & 63 \\
\hline TNF- $\alpha$ & CATCGCCGTCTCCTACCA & CCCAGATTCAGCAAAGTCCA & 199 & 56 \\
\hline$\beta$-actin & CTGGAACGGTGAAGGTGA & TTTGGAAAGGCAGGGACT & 170 & 60 \\
\hline
\end{tabular}

${ }^{1}$ Abbreviations: CDK4, cyclin-dependent kinase 4; $\mathrm{Cu}-\mathrm{Zn}$ SOD, Cu-Zn superoxide dismutase; GPX1, glutathione peroxidase 1; IGF-1, insulin-like growth factor 1; MT, metallothionein; ZO-1, zonula occludens protein-1

${ }^{2} \mathrm{AT}$ : Annealing temperature in ${ }^{\circ} \mathrm{C}$.

VIS-photometer at $260 \mathrm{~nm}$ (BioPhotometer, Eppendorf, Germany). Furthermore, purity of the total RNA extracted was determined as the E260/E280 ratio with expected values between 1.8 and 2.0. Reverse transcription was performed using the PrimeScript TM RT Reagent Kit (Takara) with a $1 \mu \mathrm{g}$ RNA sample. Expression levels of $\beta$-actin, $\mathrm{Cu}-\mathrm{Zn}$ superoxide dismutase (Cu-Zn SOD), glutathione peroxidase 1 (GPX1), metallothionein (MT), zonula occludens protein-1 (ZO-1), occludin, Caspase3, insulin-like growth factor 1 (IGF-1), and cyclin-dependent kinase 4 (CDK4) in jejuna tissue, $\beta$-actin, interferon gamma (IFN- $\gamma$ ), interleukin-1 beta (IL-1 $\beta)$, interleukin-6 (IL-6), tumor necrosis factor alpha (TNF- $\alpha$ ), nuclear factor kappa-light-chain-enhancer of activated B cells (NF- $\mathrm{kB})$, and transforming growth factor beta (TGF- $\beta$ ) in ileal tissue were analyzed by real-time quantitative PCR with SYBR Premix Ex TaqTM II (Takara), which was performed on complementary DNA samples in ninety-six-well optical plates on a CFX96TM Real-Time System (Bio-Rad). All of the primer sequences for the selected genes were showed in Table 4 . The PCR system consisted of $5 \mu \mathrm{L}$ of $2 \times \mathrm{SYBR}^{\circledR}$ premix Ex TaqTM II, $0.3 \mu \mathrm{L}$ of each forward and reverse primer $(10 \mu \mathrm{mol} / \mathrm{L}), 4 \mu \mathrm{L}$ of complementary DNA template, and $0.4 \mu \mathrm{L}$ of double distilled water. The protocols for all genes included a denaturation program (1 min at $95{ }^{\circ} \mathrm{C}$ ), amplification and quantification program repeated for 35 cycles $\left(5 \mathrm{~s}\right.$ at $95^{\circ} \mathrm{C}, 30 \mathrm{~s}$ at $52-63^{\circ} \mathrm{C}$, Table 4 ), followed by the melting curve program at $60-95{ }^{\circ} \mathrm{C}$ with a heating rate of $0.1^{\circ} \mathrm{C}$ per second and continuous fluorescence measurement.

\section{Bacterial community}

The DNA extraction, PCR amplification, illumina MiSeq sequencing, and bacterial data processing were conducted according to the procedures of Han et al. [31]. DNA extraction of ileal, cecal, and colonic contents was performed according to the instructions of a DNA Stool Mini Kit (Qiagen, Hilden, Germany). The bacterial universal V3-V4 region of the 16S RNA gene was amplified according to PCR bar-coded primers 338F (5'-ACTCCTACGGGAGGCAGCA-3') and 806R (5'-GGACTACHVGGGTWTCTAAT-3').

\section{Statistical analysis}

Results are presented as means \pm SEMs. All data were analyzed by one-way ANOVA using the general linear model procedures of SAS (SAS Institute Inc., Cary, NC, USA). Difference among treatment means was determined by Student-Newman-Keuls test. $P$ values less than 0.05 were considered significant.

\section{Abbreviations}

ADFI, average daily feed intake; ADG, average daily gain; $\mathrm{CDK} 4$, cyclin-dependent kinase 4 ; $\mathrm{Cu}-\mathrm{Zn}$ SOD, $\mathrm{Cu}-\mathrm{Zn}$ superoxide dismutase; F:G, feed:gain; GPX1, glutathione peroxidase 1; IGF-1, insulin-like growth factor 1; MT, metallothionein; Nano-ZnO, nano-zinc oxide; 
OTUs, operational taxonomic units; $\mathrm{ZnO}$, zinc oxide; $\mathrm{ZO}$ 1 , zonula occludens protein-1.

\section{ACKNOWLEDGMENTS}

We thank Dr. Shabnam Farrar (Midwestern University, USA) for critically reading the manuscript. The authors are grateful to the Zhejiang Huiqian Gaofei New Materials Share Company for providing the Nano$\mathrm{ZnO}$ and the 111 Project (B16044) for financial support.

\section{COMPETING INTERESTS} interests.

The authors declare that they have no competing

\section{REFERENCES}

1. Wijtten PJ, van der Meulen J, Verstegen MW. Intestinal barrier function and absorption in pigs after weaning: a review. Br J Nutr. 2011; 105:967-981.

2. Huang C, Song P, Fan P, Hou C, Thacker PA, Ma X. Dietary sodium butyrate decreased postweaning diarrhea by modulating intestinal permeability and changing the bacterial community in weaned piglets. J Nutr. 2015;145:2774-2780.

3. Shen J, Chen Y, Wang Z, Zhou A, He M, Mao L, Zou H, Peng Q, Xue B, Wang L, Zhang X, Wu S, Lv Y. Coated zinc oxide improves intestinal immunity function and regulates microbiota composition in weaned piglets. Br J Nutr. 2014; 111:2123-2134.

4. Wang W, Yang Q, Sun Z, Chen X, Yang C, Ma X. Advance of interactions between exogenous natural bioactive peptides and intestinal barrier and immune responses. Curr Protein Pept Sci. 2015;16:574-575.

5. Liu J, Feng X, Wei L, Chen L, Song B, Shao L. The toxicology of ion-shedding zinc oxide nanoparticles. Crit Rev Toxicol. 2016; 46:348-384.

6. Paek HJ, Lee YJ, Chung HE, Yoo NH, Lee JA, Kim MK, Lee JK, Jeong J, Choi SJ. Modulation of the pharmacokinetics of zinc oxide nanoparticles and their fates in vivo. Nanoscale. 2013; 5:11416-11427.

7. Donaldson K, Schinwald A, Murphy F, Cho WS, Duffin $\mathrm{R}$, Tran L, Poland C. The biologically effective dose in inhalation nanotoxicology. Acc Chem Res. 2013; 46:723732.

8. Kim CS, Nguyen HD, Ignacio RM, Kim JH, Cho HC, Maeng EH, Kim YR, Kim MK, Park BK, Kim SK. Immunotoxicity of zinc oxide nanoparticles with different size and electrostatic charge. Int J Nanomedicine. 2014; 9 Suppl 2:195-205.

9. Roy R, Singh SK, Das M, Tripathi A, Dwivedi PD. Tolllike receptor 6 mediated inflammatory and functional responses of zinc oxide nanoparticles primed macrophages.
Immunology. 2014; 142:453-464.

10. Wang J, Han M, Zhang G, Qiao S, Li D, Ma X. The signal pathway of antibiotic alternatives on intestinal microbiota and immune function. Curr Protein Pept Sci. 2016; 17: 785796.

11. Liang S, Sun K, Wang Y, Dong S, Wang C, Liu L, Wu Y. Role of Cyt-C/caspases-9,3, Bax/Bcl-2 and the FAS death receptor pathway in apoptosis induced by zinc oxide nanoparticles in human aortic endothelial cells and the protective effect by alpha-lipoic acid. Chem Biol Interact. 2016; 258:40-51.

12. Nagajyothi PC, Cha SJ, Yang IJ, Sreekanth TV, Kim KJ, Shin HM. Antioxidant and anti-inflammatory activities of zinc oxide nanoparticles synthesized using Polygala tenuifolia root extract. J Photochem Photobiol B. 2015; 146:10-17.

13. Chen J, Li Y, Tian Y, Huang C, Li D, Zhong Q, Ma X. Interaction between microbes and host intestinal health: modulation by dietary nutrients and gut-brain-endocrineimmune axis. Curr Protein Pept Sci. 2015;16:592-603.

14. Hill GM, Cromwell GL, Crenshaw TD, Dove CR, Ewan RC, Knabe DA, Lewis AJ, Libal GW, Mahan DC, Shurson GC, Southern LL, Veum TL. Growth promotion effects and plasma changes from feeding high dietary concentrations of zinc and copper to weanling pigs (regional study). J Anim Sci. 2000; 78:1010-1016.

15. Han M, Song P, Huang C, Rezaei A, Farrar S, Brown MA, Ma X. Dietary grape seed proanthocyanidins (GSPs) improve weaned intestinal microbiota and mucosal barrier using a piglet model. Oncotarget. 2016; 7:80313-80326. doi: 10.18632/oncotarget.13450.

16. Seil JT, Webster TJ. Antibacterial effect of zinc oxide nanoparticles combined with ultrasound. Nanotechnology. 2012; 23:495101.

17. Song ZH, Xiao K, Ke YL, Jiao le F, Hu CH. Zinc oxide influences mitogen-activated protein kinase and TGF-beta1 signaling pathways, and enhances intestinal barrier integrity in weaned pigs. Innate Immun. 2015; 21:341-348.

18. Zhu LH, Zhao KL, Chen XL, Xu JX. Impact of weaning and an antioxidant blend on intestinal barrier function and antioxidant status in pigs. J Anim Sci. 2012; 90:2581-2589.

19. Martin L, Lodemann U, Bondzio A, Gefeller EM, Vahjen W, Aschenbach JR, Zentek J, Pieper R. A high amount of dietary zinc changes the expression of zinc transporters and metallothionein in jejunal epithelial cells in vitro and in vivo but does not prevent zinc accumulation in jejunal tissue of piglets. J Nutr. 2013; 143:1205-1210.

20. Ruttkay-Nedecky B, Nejdl L, Gumulec J, Zitka O, Masarik M, Eckschlager T, Stiborova M, Adam V, Kizek R. The role of metallothionein in oxidative stress. Int $\mathrm{J}$ Mol Sci. 2013; 14:6044-6066.

21. Prasad AS. Zinc: an antioxidant and anti-inflammatory agent: role of zinc in degenerative disorders of aging. $\mathrm{J}$ Trace Elem Med Biol. 2014; 28:364-371. 
22. Hu C, Song J, Li Y, Luan Z, Zhu K. Diosmectite-zinc oxide composite improves intestinal barrier function, modulates expression of pro-inflammatory cytokines and tight junction protein in early weaned pigs. Br J Nutr. 2013; 110:681-688.

23. Liu P, Pieper R, Rieger J, Vahjen W, Davin R, Plendl J, Meyer W, Zentek J. Effect of dietary zinc oxide on morphological characteristics, mucin composition and gene expression in the colon of weaned piglets. PLoS One. 2014; 9:e91091.

24. Sargeant HR, Miller HM, Shaw MA. Inflammatory response of porcine epithelial IPEC J2 cells to enterotoxigenic E. coli infection is modulated by zinc supplementation. Mol Immunol. 2011; 48:2113-2121.

25. Vahjen W, Pieper R, Zentek J. Bar-coded pyrosequencing of $16 \mathrm{~S}$ rRNA gene amplicons reveals changes in ileal porcine bacterial communities due to high dietary zinc intake. Appl Environ Microbiol. 2010; 76:6689-6691.

26. Vahjen W, Pieper R, Zentek J. Increased dietary zinc oxide changes the bacterial core and enterobacterial composition in the ileum of piglets. J Anim Sci. 2011; 89:2430-2439.

27. Pieper R, Vahjen W, Neumann K, Van Kessel AG, Zentek J. Dose-dependent effects of dietary zinc oxide on bacterial communities and metabolic profiles in the ileum of weaned pigs. J Anim Physiol Anim Nutr (Berl). 2012; 96:825-833.

28. Hojberg O, Canibe N, Poulsen HD, Hedemann MS, Jensen BB. Influence of dietary zinc oxide and copper sulfate on the gastrointestinal ecosystem in newly weaned piglets. Appl Environ Microbiol. 2005; 71:2267-2277.

29. Starke IC, Pieper R, Neumann K, Zentek J, Vahjen W. The impact of high dietary zinc oxide on the development of the intestinal microbiota in weaned piglets. FEMS Microbiol Ecol. 2014; 87:416-427.

30. Luche S, Eymard-Vernain E, Diemer H, Van Dorsselaer A, Rabilloud T, Lelong C. Zinc oxide induces the stringent response and major reorientations in the central metabolism of Bacillus subtilis. J Proteomics. 2016; 135:170-180.
31. Shin JH, Helmann JD. Molecular logic of the Zur-regulated zinc deprivation response in Bacillus subtilis. Nat Commun. 2016; 7:12612.

32. Prieto ML, O’Sullivan L, Tan SP, McLoughlin P, Hughes $\mathrm{H}$, O'Donovan O, Rea MC, Kent RM, Cassidy JP, Gardiner GE, Lawlor PG. Evaluation of the efficacy and safety of a marine-derived Bacillus strain for use as an infeed probiotic for newly weaned pigs. PLoS One. 2014; 9:e88599.

33. Xu L, Xu XW, Meng FX, Huo YY, Oren A, Yang JY, Wang CS. Halomonas zincidurans sp. nov., a heavy-metaltolerant bacterium isolated from the deep-sea environment. Int J Syst Evol Microbiol. 2013; 63:4230-4236.

34. Huo YY, Li ZY, Cheng H, Wang CS, Xu XW. High quality draft genome sequence of the heavy metal resistant bacterium Halomonas zincidurans type strain B6(T). Stand Genomic Sci. 2014; 9:30.

35. Kim S, Chae Y, Kang Y, An YJ, Yoon Y. Assessing the toxicity and the dissolution rate of zinc oxide nanoparticles using a dual-color Escherichia coli whole-cell bioreporter. Chemosphere. 2016; 163:429-437.

36. Liedtke J, Vahjen W. In vitro antibacterial activity of zinc oxide on a broad range of reference strains of intestinal origin. Vet Microbiol. 2012; 160:251-255.

37. Fan P, Li L, Rezaei A, Eslamfam S, Che D, Ma X. Metabolites of Dietary Protein and Peptides by Intestinal Microbes and their Impacts on Gut. Curr Protein Pept Sci. 2015;16:646-654.

38. Tso CP, Zhung CM, Shih YH, Tseng YM, Wu SC, Doong RA. Stability of metal oxide nanoparticles in aqueous solutions. Water Sci Technol. 2010; 61:127-133. 